Linha D'Água (Online), São Paulo, v. 33, n. 2, p. 69-90, maio-ago. 2020

\title{
DO TEATRO AOS QUADRINHOS: UMA EXPERIÊNCIA DE LEITURA LITERÁRIA E ESCRITA MULTIMODAL
}

\author{
FROM THEATER PLAYS TO COMICS: A LITERARY READING AND \\ MULTIMODAL WRITING EXPERIENCE
}

\author{
André Alexandre Padilha Leitão* \\ Instituto Federal de Pernambuco Campus Garanhuns, Garanhuns, PE, Brasil
}

\begin{abstract}
Resumo: 0 objetivo desse trabaho é apresentar os resultados de uma das etapas do projeto de pesquisa e ensino Mostre a Língua. Abordagem intersemiótica da literatura: da compreensão poética à escrita autoral em desenvolvimento no Instituto Federal de Pernambuco Campus Garanhuns desde 2019.0 corpus da pesquisa foi composto pela produção de quatro (04) histórias em quadrinhos baseadas nas peças Os dous ou 0 inglês maquinista e 0 juiz da paz da roça, ambas de Martins Pena. 0 recorte escollido apresenta os dados do trabahlho a partir do texto 0 juiz da paz da roça. Os sujeitos da pesquisa foram 36 estudantes do $2^{\circ}$ ano do Ensino Médio Integrado em Informática do Campus Garanhuns. 0 procedimento metodológico baseou-se na proposta de sequência didática por Dolz, Noverraz e Schneuwly (2004) e das estratégias de retextualização de Marcuschi (2004) Os resultados demonstraram que a representação dos elementos da narrativa verbal quando transpostos para o texto multimodal adequaram-se à proposta e ao propósito do gênero produzido, apresentando falhas relativas a alguns aspectos técnicos da elaboração de quadrinhos, tais como falta de dinamismo na expressão dos personagens e ausência de foco nos cenários, sem contudo prejuddicar a acçõo de linguagem, conforme definida por Bronckart (2003).
\end{abstract}

Palavras-chave: produção textual; quadrinhos; retextualização; sequência didática; multiletramentos.

\begin{abstract}
The purpose of this paper is to present the results of one of the stages of the research and teachin project and Mostre a Lingua. Intersemiotic approach to literature: from poetic comprehension to authorial writing under development at the Federal Institute of Pernambuco Campus Garanhuns since 2019. The research corpus was composed by the production of four (04) comics based on the pieces 0 juiz de paz da roça e Os dous ou o inglês maquinista, both from Martins Pena. The data chosen here presents results from the text 0 juiz de paz da roça. The research subjects were 36 students of the 2 nd year of Integrated High School in Informatics of Campus Garanhuns. The methodological procedure was based on the didactic sequence proposed by Dolz, Noverraz and Schneuwly (2004) and Marcuschi's retextualization strategies (2004). The results showed that the representation of verbal narrative elements when transposed into the multimodal text was adequate to the proposal and purpose of the produced genre, presenting flaws related to some technical aspects of comics elaboration, such as lack of dynamism in the expression of the characters and absence of focus in the scenarios, without however harming the language action, as defined by Bronckart ( 2003).
\end{abstract}

Keywords: Text Production; Comics; Retextualization; Didactic Sequence; Multiliteracies.

* Professor do Ensino Básico, Técnico e Tecnológico do Instituto Federal de Pernambuco Campus Garanhuns - IFPE, Garanhuns, PE, Brasil; https://orcid.org/0000-0002-7396-4420; andre.padilha@garanhuns.ifpe.edu.br

hitp://dx.doi.org/10.11606/issn.2236-4242.v33i2p69-90

Todo conteúdo da Linha D'Água está sob Licença Creative Commons Attribution-NonCommercial 4.0 International License 
Linha D'Água (Online), São Paulo, v. 33, n. 2, p. 69-90, maio-ago. 2020

\section{Introdução}

O presente trabalho tem por objetivo apresentar os resultados de uma das etapas do projeto de pesquisa e ensino intitulado Mostre a Lingua. Abordagem intersemiótica da literatura: da compreensão poética à escrita autoral desenvolvido no Instituto Federal de Pernambuco Campus Garanhuns (IFPE Campus Garanhuns). $\mathrm{O}$ recorte da pesquisa corresponde aos trabalhos desenvolvidos com estudantes do $2^{\circ}$ ano do Ensino Médio Integrado do IFPE Campus Garanhuns a partir da quadrinização das peças teatrais "O juiz de paz da roça" e "Os dous ou o inglês maquinista", ambas de Martins Pena.

A primeira parte discute os possíveis lugares ocupados pela literatura na escola a partir da publicação dos Parâmetros Curriculares Nacionais (PCN) em 1999, cuja ênfase reside no estudo da língua sem a devida articulação com as manifestações literárias. A segunda parte discute os conceitos de letramento literário, multiletramentos e retextualização como componentes indispensáveis para a educação linguística. O procedimento metodológico detalha, a partir do procedimento sequência didática, proposto por Dolz, Noverraz e Schneuwly (2004), de que modo articulamos o lugar da literatura na escola e a promoção de letramentos por meio de uma atividade de retextualização. Por fim, a análise dos resultados indica a centralidade da retextualização para o desenvolvimento do letramento literário e dos multiletramentos a partir das estratégias de eliminação, inserção e substituição.

A nossa conclusão destaca a necessidade de formação de uma comunidade de leitores na escola, a necessidade da reescrita textual como procedimento para melhoria da habilidade escrita e, também, a inclusão, enquanto conteúdo programático, das tecnologias digitais nos componentes curriculares, não apenas nas aulas de línguas.

\section{0 (não)lugar da literatura nas aulas de língua portuguesa}

Em artigo intitulado "Alguns descompassos no ensino de literatura: documentos e práticas oficiais", Pinto (2014) pondera sobre a questão da leitura do texto literário na escola. Conforme a autora, 
[...] a leitura literária não "serve" a nenhum objetivo que não seja a leitura em si, sua polissemia intrínseca pede um leitor atento, nada mais, às vezes nem isso, podendo mesmo a experiência de leitura ser "vaga" - ao leitor, na literatura, é permitido flanar com a atenção solta de alguém que vai encontrando surpresas a cada página, ou não! Nada mais contrário, portanto, à noção de "proficiência no uso da língua", com toda a sua carga pragmática, necessária, sem dúvida, para inúmeros procedimentos de leitura e escrita, mas inadequada quando se trata de trabalhar com a formação do leitor literário. (pág. 464)

Esse posicionamento nos diz muito sobre a atual situação do ensino de literatura na escola, em particular no Ensino Médio e especialmente após o que a autora aponta como a virada pragmática a partir da década de 80 . Com a ênfase no desenvolvimento da proficiência leitora por meio de gêneros textuais não literários, as orientações metodológicas oficiais retiraram a ênfase, de certo modo, da literatura como parte essencial do componente curricular língua portuguesa para o desenvolvimento das habilidades de linguagem que precisam ser construídas em ambiente escolar.

Essa falta de ênfase pode ser comprovada tanto nos Parâmetros Curriculares Nacionais: Ensino Médio ${ }^{1}$ (BRASIL, 1999) quanto no PCNs+ Ensino Médio: orientações educacionais complementares aos Parâmetros Curriculares Nacionais ${ }^{2}$ (BRASIL, 2002). Em ambos os documentos, observamos um forte empenho em reconhecer a linguagem como espaço constituído pelo dialogismo bakhtiniano. No entanto, esse conceito parece ter sido cuidadosamente selecionado em tais documentos para refletir todas as outras manifestações de linguagem, exceto a literatura. Parece-nos que a elaboração de tais orientações metodológicas oficiais negligenciou o espaço singular no qual o sujeito pode constituir-se "discursivamente, apreendendo as vozes sociais em que está imerso, e, ao mesmo tempo, suas inter-relações dialógicas" (FIORIN, 2018) por meio do texto literário.

Essa condição de "prima pobre" (ou talvez, "rica demais") do componente curricular língua portuguesa após a virada pragmática, expressa nos PCNEM e PCNEM+ suscitou discussões as mais diversas. Por essa razão, em 2006, surgem

\footnotetext{
1 Doravante, PCNEM

2 Doravante, PCNEM+
}

LEITÃO, A. A. P. Do teatro aos quadrinhos: uma experiência de leitura literária e escrita multimodal Todo conteúdo da Linha D’Água está sob Licença Creative Commons Attribution-NonCommercial 4.0 International License 
Linha D'Água (Online), São Paulo, v. 33, n. 2, p. 69-90, maio-ago. 2020

as Orientações Curriculares para o Ensino Médio ${ }^{3}$ (BRASIL, 2006), com um capítulo que reconhece as falhas em relação ao lugar dedicado à literatura nos PCNEM e PCNEM+. Conforme o OCNEM, temos que:

$\mathrm{Na}$ defesa, pois, da especificidade da Literatura, torna-se necessário agora ratificar a importância de sua presença no currículo do ensino médio (importância que parece ter sido colocada em questão), assim como atualizar as discussões que têm sido travadas desde os últimos PCN. (BRASIL, 2006, págs. 50-51)

Mesmo com esse avanço, devemos ainda nos perguntar (e essa pergunta permeia as considerações do OCNEM): Afinal, qual a função da literatura na escola? $\mathrm{E}$ com isso, poderíamos correr o risco de voltar à citação inicial deste trabalho e iniciarmos um círculo vicioso. Entretanto, buscando responder essa pergunta na esteira da finalidade do estudo da literatura, consideramos pertinentes aquilo que Cosson (2002, pág. 166) aponta enquanto razões do apagamento da literatura na escola. Para o autor:

Tradicionalmente, as relações entre literatura e escola se dava, por meio de uma parceria. Da escola, a literatura recebia a garantia de manutenção do cânone, através da confirmação dos protocolos de leitura dos críticos, e de formação dos consumidores produtores que alimentavam seu sistema. Da literatura, a escola requeria um modelo de bem escrever para o ensino da língua materna e um material adequado para o ensino da leitura e da cultura como representação da nação ou da humanidade.

Diante disso, encontramos razões para quebrar a possibilidade de um círculo vicioso entendendo que foi a insistência na manutenção de um cânone (e, por consequência, a linguagem utilizada por esses modelos) que propiciou uma espécie de "decadência" do estudo da literatura na escola. Cremos que isso tenha sido devido, principalmente, após a popularização de inúmeras tecnologias que permitiram à leitura literária ser substituída pelas adaptações cinematográficas, por exemplo. Atualmente é possível assistir ao Hamlet a partir de uma adaptação em realidade

3 Doravante, OCNEM

LEITÃO, A. A. P. Do teatro aos quadrinhos: uma experiência de leitura literária e escrita multimodal Todo conteúdo da Linha D’Água está sob Licença Creative Commons Attribution-NonCommercial 4.0 International License 
Linha D’Água (Online), São Paulo, v. 33, n. 2, p. 69-90, maio-ago. 2020

virtual (Rei Leão) ou acompanharmos a saga dos heróis da Marvel, consideradas em sua forma original como Graphic Novels ou romance gráfico, nas telas de cinema. Claramente ao mencionarmos a tecnologia, entendemos que essa não se limita ao cinema: Machado de Assis, Cervantes, Poe, para citarmos poucos exemplos, foram transpostos para os quadrinhos e também foram adaptados para as animações.

Se, conforme Pinto (2014, pág. 464), “a leitura literária não 'serve' a nenhum objetivo que não seja a leitura em si”, é a mesma autora que nos recupera essa falta de pragmatismo da leitura literária ao afirmar que a polissemia constituinte do texto literário não exige nada além de um leitor proficiente. Porém, como proporcionar lugares e espaços construtores desse tipo de leitor nas aulas de língua portuguesa? Como alinhar a tecnologia que adapta a literatura às telas de cinema e outras semioses ao trabalho didático de promoção da leitura do texto literário?

Aventamos a hipótese de que uma das melhores maneiras (e, certamente, não a única) de obter esse leitor proficiente é permitindo que o estudante possa interferir, modificar o texto a partir do procedimento de retextualização, ao invés de apenas responder perguntas sobre o texto.

O conceito de retextualização, empregado por Travaglia (1993) e retomado por Marcuschi (2004), diz respeito a "um processo que envolve operações complexas que interferem tanto no código como no sentido e evidenciam uma série de aspectos nem sempre bem-compreendidos da relação oralidade-escrita." (MARCUSCHI, 2004, pág. 46)

Devemos observar, porém, que Marcuschi (2004) ao se apropriar desse termo e realizar o estudo apresentado no livro " $\mathrm{Da}$ fala para escrita: atividades de retextualização", tem por objetivo observar os aspectos presentes na passagem de um texto da modalidade oral para um texto na modalidade escrita. Todavia, o autor destaca que são possíveis quatro tipos de possibilidades de retextualização: (1) fala-escrita; (2) fala-fala; (3) escrita-fala e (4) escrita-escrita e não apenas aquela a que ele se dedica a investigar na referida obra. Por discutirmos, neste trabalho, o lugar do texto literário na escola, o tipo de retextualização proposta que possibilite a confirmação da hipótese levantada acima será a do tipo (4) escrita-escrita.

Resta-nos responder, ainda, a duas perguntas: (1) Como inserir a tecnologia no processo de retextualização do texto literário?, já que as tecnologias que

LEITÃO, A. A. P. Do teatro aos quadrinhos: uma experiência de leitura literária e escrita multimodal Todo conteúdo da Linha D'Água está sob Licença Creative Commons Attribution-NonCommercial 4.0 International License 
Linha D'Água (Online), São Paulo, v. 33, n. 2, p. 69-90, maio-ago. 2020

permitem as adaptações do texto literário provocam um certo desinteresse em se trabalhar com as obras originais em sala de aula e (2) Quais gêneros de textos consideramos possíveis para esse processo?, visto que retextualizar não é sinônimo de reescrever e, portanto, a atividade didática não pode consistir em interferir no texto escrito de um gênero para um texto modificado (retextualilzado) do mesmo gênero. Discutiremos isso em detalhes na seção 3 Procedimento Metodológico. Antes, porém, precisamos discutir a relevância do conceito de letramento para o processo de retextualização.

\section{Dos letramentos à retextualização}

O processo de $\mathrm{r}^{\circ}$ etextualização como procedimento didático precisa considerar alguns aspectos a fim de que a produção final, isto é, o texto retextualizado, possa apresentar elementos linguísticos e discursivos passíveis de avaliação educacional. Isto porque o processo é capaz de revelar em que medida a atividade de compreensão textual dos gêneros envolvidos - como também seus aspectos de conteúdo, estilo e construção composicional (BAKHTIN, 2003) - foi bem-sucedida. Marcuschi (2004, pág. 54) chama esses aspectos de variáveis e consistem:

i. no propósito ou objetivo da retextualização;

ii. na relação entre o produtor do texto original e o transformador;

iii. na relação tipológica entre o gênero textual original e o gênero da retextualização;

iv. nos processos de formulação típicos de cada modalidade.

Consideramos, no processo de ensino-aprendizagem, que o reconhecimento dessas variáveis são reveladoras de índices de letramento, já que reconhecê-las e aplicá-las são práticas sociais envolvendo a leitura e a escrita. No entanto, precisamos esclarecer a quais letramentos estamos nos referindo, pois é inevitável discutir literatura na escola sem mencionar o letramento literário do mesmo modo que seria insensato incluir a tecnologia digital no processo de produção textual sem apontarmos algumas questões relativas aos multiletramentos.

LEITÃO, A. A. P. Do teatro aos quadrinhos: uma experiência de leitura literária e escrita multimodal Todo conteúdo da Linha D’Água está sob Licença Creative Commons Attribution-NonCommercial 4.0 International License 
Linha D'Água (Online), São Paulo, v. 33, n. 2, p. 69-90, maio-ago. 2020

Cosson (2006, pág. 12) concebe o letramento literário como um processo que "se faz via textos literários [...] como forma de assegurar seu efetivo domínio". Para ele, o letramento literário tem por objetivo o fortalecimento e a ampliação da educação literária a partir da formação de uma comunidade de leitores (COSSON, 2006).

Em verbete do Glossário Ceale, o autor aponta quatro características fundamentais para o desenvolvimento do letramento literário:

Em primeiro lugar, não há letramento literário sem o contato direto do leitor com a obra, ou seja, é preciso dar ao aluno a oportunidade de interagir ele mesmo com as obras literárias. Depois, o processo do letramento literário passa necessariamente pela construção de uma comunidade de leitores, isto é, um espaço de compartilhamento de leituras no qual há circulação de textos e respeito pelo interesse e pelo grau de dificuldade que o aluno possa ter em relação à leitura das obras. Também precisa ter como objetivo a ampliação do repertório literário, cabendo ao professor acolher no espaço escolar as mais diversas manifestações culturais, reconhecendo que a literatura se faz presente não apenas nos textos escritos, mas também em outros tantos suportes e meios. Finalmente, tal objetivo é atingido quando se oferecem atividades sistematizadas e contínuas direcionadas para o desenvolvimento da competência literária, cumprindo-se, assim, o papel da escola de formar o leitor literário. (COSSON, online)

Nesse sentido, observamos que essas quatro características são usos efetivos da leitura e da escrita (ainda que esta última esteja implícita nos aspectos acima apontados) em práticas sociais, isto é, são práticas de letramento e precisam estar em consonância com as variáveis envolvidas no processo de retextualização, de modo que:

1. o objetivo da retextualização esteja alinhado com o objetivo da ampliação do repertório literário e também linguístico;

2. a relação entre o produtor do texto original e o transformador esteja alinhado com o contato direto com a obra e seu autor e a construção de uma comunidade de leitores;

3. a relação tipológica entre o gênero textual original e o gênero da retextualização assim como os processos de formulação típicos de cada modalidade

LEITÃO, A. A. P. Do teatro aos quadrinhos: uma experiência de leitura literária e escrita multimodal Todo conteúdo da Linha D'Água está sob Licença Creative Commons Attribution-NonCommercial 4.0 International License 
Linha D'Água (Online), São Paulo, v. 33, n. 2, p. 69-90, maio-ago. 2020

estejam alinhados com atividades sistematizadas e contínuas direcionadas para o desenvolvimento da competência literária.

Defendemos que a partir da articulação entre as variáveis propostas por Marcuschi (2004) e as características apontadas por Cosson (online), é possível o desenvolvimento de letramentos por meio da modificação do texto literário mediado pelo processo de retextualização. Reconhecemos, contudo, que uma atividade didática proposta a modificar um texto literário, seja ele um conto, um poema ou uma fábula, precisa ser estruturada de modo que o próprio processo envolva a produção de novos significados. Nesse sentido, os sujeitos partícipes do processo precisam ser considerados como autores e não somente como estudantes cuja tarefa é responder algo que se encontra explícito no próprio texto, sem nenhuma possibilidade de expressão de sua voz social. Isto tem implicações profundas porque, conforme aponta Bronckart (2003, pág. 320):

$\mathrm{O}$ autor, como agente da ação da linguagem que se concretiza num texto empírico, é, aparentemente, responsável pela totalidade das operações que darão a esse texto seu aspecto definitivo: é, aparentemente, ele quem decide sobre o conteúdo temático a ser semiotizado, quem escolhe um modelo de gênero adaptado à situação de comunicação, quem seleciona e organiza os tipos de discursos, quem gerencia os diversos mecanismos de textualização. (Grifo nosso)

Assim, se o autor é responsável pelas operações que darão ao texto seu "aspecto definitivo", ele torna-se um designer ativo de significados. Esses significados envolvem diversos e distintos tipos, podendo ser:

1. o significado linguístico (entonação, ritmo, modalidade, metáfora, escolha lexical, coesão, coerência, etc);

2. o significado visual (imagens, layouts, cores, traços, fontes, etc);

3. o significado auditivo (músicas, efeitos sonoros, etc);

4. o significado gestual (linguagem corporal, sensualidade, olhar, etc);

5. o significado espacial (espaços ambientais, espaços arquitetônicos, etc) e

LEITÃO, A. A. P. Do teatro aos quadrinhos: uma experiência de leitura literária e escrita multimodal Todo conteúdo da Linha D'Água está sob Licença Creative Commons Attribution-NonCommercial 4.0 International License 
Linha D’Água (Online), São Paulo, v. 33, n. 2, p. 69-90, maio-ago. 2020

6. o significado de modelos multimodais (integração de todos os modos anteriores). (GRUPO DE NOVA LONDRES, 1996, online)

Todos esses elementos relacionam-se com "o quê" de uma pedagogia dos multiletramentos. Ou seja, o que os alunos precisam aprender e o que as escolas precisam ensinar para que os primeiros possam perceber o aprendizado como um processo de construção de significados ativo e dinâmico. Porém, é ainda preciso saber de que forma esses elementos se traduzem no "como" de uma pedagogia que considere tipos diversos de significados. Para tanto, conforme aponta o Grupo de Nova Londres (1996), é preciso incluir quatro componentes relacionados à forma pela qual é possível transformar esses significados em um modo de agir, socialmente, pela linguagem, a saber:

1. Prática situada, isto é, aquela que se aproxima da construção de sentidos na vida real, na esfera pública, nos locais de trabalho;

2. Instrução aberta, isto é, aquela na qual os alunos desenvolvem uma metalinguagem explícita para trabalhar com os elementos do design (com o "quê" da pedagogia dos multiletramentos);

3. Modelo crítico, isto é, aquele que interpreta o contexto social e o propósito dos designs de significados $\mathrm{e}$

4. Prática transformada, isto é, aquela na qual os alunos, como produtores de significado, tornam-se designers do futuro social (GRUPO DE NOVA LONDRES, 1996, online).

Como podemos constatar, tanto os elementos do "quê" quanto os elementos do "como", nesta proposta, são responsáveis por um processo de aprendizagem da leitura e da escrita que envolve, acima de tudo, negociação entre as partes envolvidas.

Assim, compreendemos o conceito de multiletramentos como sendo os recursos representacionais de construção de significado constantemente atualizados pelos usuários com vistas a atingir os vários propósitos culturais e sociocomunicativos. Tais recursos incluem a linguagem verbal, as imagens, os sons, o espaço

LEITÃO, A. A. P. Do teatro aos quadrinhos: uma experiência de leitura literária e escrita multimodal Todo conteúdo da Linha D'Água está sob Licença Creative Commons Attribution-NonCommercial 4.0 International License 
Linha D'Água (Online), São Paulo, v. 33, n. 2, p. 69-90, maio-ago. 2020

geográfico e o próprio corpo para construir os significados. Essa construção só é possível por meio de práticas situadas, da educação formal, de um pensamento crítico acerca dos próprios significados com o objetivo de transformá-los, de usá-los como modos de agir, socialmente, pela linguagem

Diante do exposto, responderemos as duas perguntas feitas na seção anterior: (1) Como inserir a tecnologia no processo de retextualização do texto literário? e (2) Quais gêneros de textos consideramos possíveis para esse processo? na seção seguinte.

\section{Procedimento metodológico}

A metodologia empregada visa responder de que modo a tecnologia pode ser usada no processo de retextualização de um texto literário bem como os gêneros utilizados no processo e está fundamentada no modelo de sequência didática proposto por Dolz, Noverraz e Schneuwly (2004).

Os sujeitos da pesquisa foram 36 estudantes do $2^{\circ}$ ano do Ensino Médio Integrado em Informática do IFPE Campus Garanhuns. O corpus da pesquisa foi composto pela produção de quatro (04) histórias em quadrinhos a partir das peças "Os dous ou O Inglês Maquinista" e "O juiz da paz da roça", ambas de Martins Pena. O recorte analisado nesse trabalho enfoca apenas os trabalhos produzidos a partir da peça "O juiz de paz da roça”, embora a sequência didática tenha sido aplicada para todos os quatro grupos envolvidos.

A seleção do gênero peça teatral justificou-se por duas razões: a primeira porque o $2^{\circ}$ ano do Ensino Médio apresenta o teatro romântico como parte do componente curricular (Literatura; Romantismo) e a segunda porque, em razão da tipologia predominante dialogal presente no gênero, consideramos que as interferências no texto original durante o processo de retextualização são capazes de acrescentar aspectos inexistentes na peça, como por exemplo a presença de um narrador, ou mesmo a edição de certos trechos para adequação ao gênero a ser retextualizado.

A apresentação da situação deu-se com a contextualização do gênero peça teatral, sua estrutura geral a partir do reconhecimento das sequências dialogadas e das descrições das cenas. $\mathrm{O}$ contexto histórico e os aspectos que as vinculam ao

LEITÃO, A. A. P. Do teatro aos quadrinhos: uma experiência de leitura literária e escrita multimodal Todo conteúdo da Linha D’Água está sob Licença Creative Commons Attribution-NonCommercial 4.0 International License 
Linha D’Água (Online), São Paulo, v. 33, n. 2, p. 69-90, maio-ago. 2020

Romantismo já haviam sido explorados anteriormente, visto que, didaticamente, o teatro romântico pertence à terceira geração do Romantismo brasileiro. Após os estudos desses aspectos do gênero, a turma foi dividida em quatro grupos de nove integrantes e a leitura das peças foi feita em dois encontros.

No segundo encontro, propusemos a seguinte questão aos estudantes: Como vocês transformariam essa pę̧a teatral em uma história em quadrinhos? As respostas foram unânimes em apontar que os diálogos ficariam em balões para cada personagem, como na peça. Ainda no segundo encontro, após essa discussão, trouxemos três exemplos de histórias em quadrinhos, retiradas da internet ${ }^{4}$. Esses exemplares foram analisados em conjunto com os estudantes, visando identificar algumas características anteriormente não apontadas, tais como a diferença entre balões de pensamento e de diálogos, a voz do narrador (quadros de texto) da história, o enquadramento dos personagens, presença de onomatopeias, tipo de cor (fria/ quente/clara/escura/cinza) e o cenário.

Por ser um gênero comum aos estudantes, não houve dificuldade em reconhecimento dessas características no momento da leitura/análise em sala de aula. Este segundo encontro foi finalizado com a proposta da produção inicial: retextualizar as peças teatrais em questão para o gênero história em quadrinhos. Propusemos a utilização do software LibreOffice Draw por ser livre e de fácil manipulação para inserção das imagens e quadros. No entanto, deixamos que os estudantes ficassem livres para escolher a tecnologia que melhor se adequasse a cada grupo para criação dos personagens, cenários, etc.

Os módulos da sequência didática foram trabalhados a partir das dificuldades observadas na produção inicial e nas demais reescritas ao longo de uma unidade letiva (dois meses). A cada encontro, além do conteúdo programático previsto na disciplina, reservamos tempo para que os estudantes apresentassem suas produções e houvessem as devidas correções. Ao todo, foram oito encontros para o trabalho com os módulos.

$4 \quad$ O IFPE Campus Garanhuns possui computador com acesso à internet e datashow em todas as salas de aulas, dispensando, assim, a impressão de exemplares ou mesmo a presença física dos mesmos. O acesso foi feito através dos endereços: <http://baixarquadrinhos.com> e <http://turmadamonica.uol.com.br/quadrinhos/>.

LEITÃO, A. A. P. Do teatro aos quadrinhos: uma experiência de leitura literária e escrita multimodal Todo conteúdo da Linha D’Água está sob Licença Creative Commons Attribution-NonCommercial 4.0 International License 
Linha D'Água (Online), São Paulo, v. 33, n. 2, p. 69-90, maio-ago. 2020

Nesse sentido, no que se refere à produção textual escrita, houve correção apenas em alguns casos em que a quantidade de diálogos por quadro estava excessiva ou havia algum erro de digitação. Como o texto teatral é essencialmente dialogado, isso permitiu que os estudantes focassem sua atenção nos aspectos visuais que precisariam ser criados. Além disso, por se tratar de um gênero multimodal, os aspectos relativos à composição visual do texto produzido (a história em quadrinhos propriamente dita) foram mais explorados em cada um dos módulos.

Diante disso, os módulos enfatizaram:

1. tamanho das fontes utilizadas nos balões de diálogo;

2. enquadramento do personagem que fala na cena;

3. expressões faciais e corporais dos personagens;

4. uniformidade no tamanho dos quadros;

5. posição dos quadros narrativos nas cenas;

6. posição dos balões de diálogos dos personagens;

A produção final culminou na apresentação pública e avaliação das duas peças retextualizadas para quatro histórias em quadrinhos. Professores convidados para participarem como avaliadores desses e de outros trabalhos no projeto Mostre a Língua ${ }^{5}$ fizeram a análise dos trabalhos e conversaram com os estudantes, proporcionando, assim, o reconhecimento da autoria, no sentido expresso por Bronckart (2003) citado anteriormente, dos textos retextualizados produzidos.

\section{Resultados e discussão}

Para as quatro histórias em quadrinhos produzidas, no que se refere à retextualização do texto escrito, as estratégias de eliminação, inserção e substituição foram as mais frequentes, posto que alguns grupos buscaram resumir a quantidade de

5 O I Mostre a Língua ocorreu dias 17 e 18 de outubro nas dependências do IFPE Campus Garanhuns. Os trabalhos finais de todas as turmas participantes podem ser vistos no seguinte endereço eletrônico: <bit.ly/mostrealingua> no menu Produções.

LEITÃO, A. A. P. Do teatro aos quadrinhos: uma experiência de leitura literária e escrita multimodal Todo conteúdo da Linha D’Água está sob Licença Creative Commons Attribution-NonCommercial 4.0 International License 
Linha D’Água (Online), São Paulo, v. 33, n. 2, p. 69-90, maio-ago. 2020

diálogos ou a fala dos personagens, inserir alguma onomatopeia, ou mesmo eliminar alguns trechos da peça, como podemos ver nos quadros 1 e 2 a seguir.

No Quadro 1, temos as estratégias de eliminação com vistas a simplificação, como indicamos nos trechos sublinhados. No texto original, eles são seguidos de notas de rodapé com as devidas explicações. A palavra Jacuba, por exemplo, traz a seguinte explicação: Bebida feita de água, farinha, açúcar e mel. Os limões, conforme a própria explicação dada, não faria sentido para composição da bebida. Desse modo, o vocábulo Jacuba foi eliminado e a justificativa dos limões nos quadrinhos foi criada: preparo de uma salada. A inserção desse trecho pelos estudantes do grupo demonstram também o emprego da estratégia de inserção com vistas a uma maior clareza da cena.

A substituição com fins de adequação ao contexto no qual os personagens estão inseridos (uma roça, um sítio, um lugar rural no interior) também foi adequadamente realizada, como notamos nos trechos indicados por ${ }^{* *}$ no Quadro 1. O texto original traz as expressões meu pai e minha mãe e foram substituídos por mainha e painho, empregando-se, nesse caso, a variedade linguística do nordeste e, particularmente, do estado de Pernambuco para os vocativos parentais.

A estratégia de inserção empregada pelo Grupo 1 utilizou as marcações indicativas da ação dos atores em cena, destacadas em itálico no Quadro 1, e as transformou na fala de um narrador, inexistente na peça teatral. Consideramos o uso dessa estratégia interessante porque houve a percepção dos estudantes acerca do problema de representar a mudança de cena em um gênero textual estático.

Em relação ao tamanho das fontes utilizadas, esse grupo foi um dos únicos que manteve, majoritariamente, a uniformidade desde a produção inicial. Por usarem o programa Gacha Studio para desenho dos personagens, o enquadramento destes na cena, as expressões faciais representaram de modo adequado o que foi interpretado pelos estudantes sobre o estado de humor de cada personagem na peça. Durante os módulos, o Grupo 1 teve dificuldades em relação à uniformidade no tamanho dos quadros como também na posição dos balões de diálogos dos personagens. Os quadrinhos inicialmente estavam com tamanhos diferentes e os balões de diálogos, em algumas cenas, cobriam o rosto dos personagens. No entanto, a

LEITÃO, A. A. P. Do teatro aos quadrinhos: uma experiência de leitura literária e escrita multimodal Todo conteúdo da Linha D'Água está sob Licença Creative Commons Attribution-NonCommercial 4.0 International License 
Linha D’Água (Online), São Paulo, v. 33, n. 2, p. 69-90, maio-ago. 2020

partir das correções feitas durantes os módulos, a produção final desse grupo não apresentou mais tais problemas.

\section{Trecho original: $O$ juiz de paz da roça ${ }^{6}$}

CENA 1

Sala com porta porta no fundo. No meio uma mesa, junto da qual estarão cosendo Maria Rosa e Aninha.

MARIA ROSA - Teu pai hoje tarda muito.

ANINHA - Ele disse que tinha hoje muito que fazer.

MARIA ROSA - Pobre homem! Mata-se com tanto trabalho! É quase meio-dia e ainda não voltou. Desde as quatro horas da manhã que saiu; está só com uma xícara de café.

ANINHA - ${ }^{* *}$ Meu pai quando principia um trabalho não gosta de o largar, $\mathrm{e}^{* *}$ minha mãe bem sabe que ele tem só a Agostinho.

MARIA ROSA - É verdade. Os meias-caras agora estão tão caros! Quando havia valongo eram mais baratos.

ANINHA — * Meu pai disse que quando desmanchar o mandiocal grande há-de comprar uma negrinha para mim.

MARIA ROSA — Também já me disse.

ANINHA - ${ }^{* *}$ Minha mãe já preparou a jacuba para meu pai?

MARIA ROSA - É verdade! De que ia me esquecendo! Vai aí fora e traz dois limões (Aninha sai.)

Se o Manuel João viesse e não achasse a jacuba pronta, tínhamos campanha velha. Do que me tinha esquecido! (Entra Aninha.)

[continua]

6 Referência completa na seção Referências.

LEITÃO, A. A. P. Do teatro aos quadrinhos: uma experiência de leitura literária e escrita multimodal Todo conteúdo da Linha D'Água está sob Licença Creative Commons Attribution-NonCommercial 4.0 International License 
Linha D'Água (Online), São Paulo, v. 33, n. 2, p. 69-90, maio-ago. 2020

[continuação]

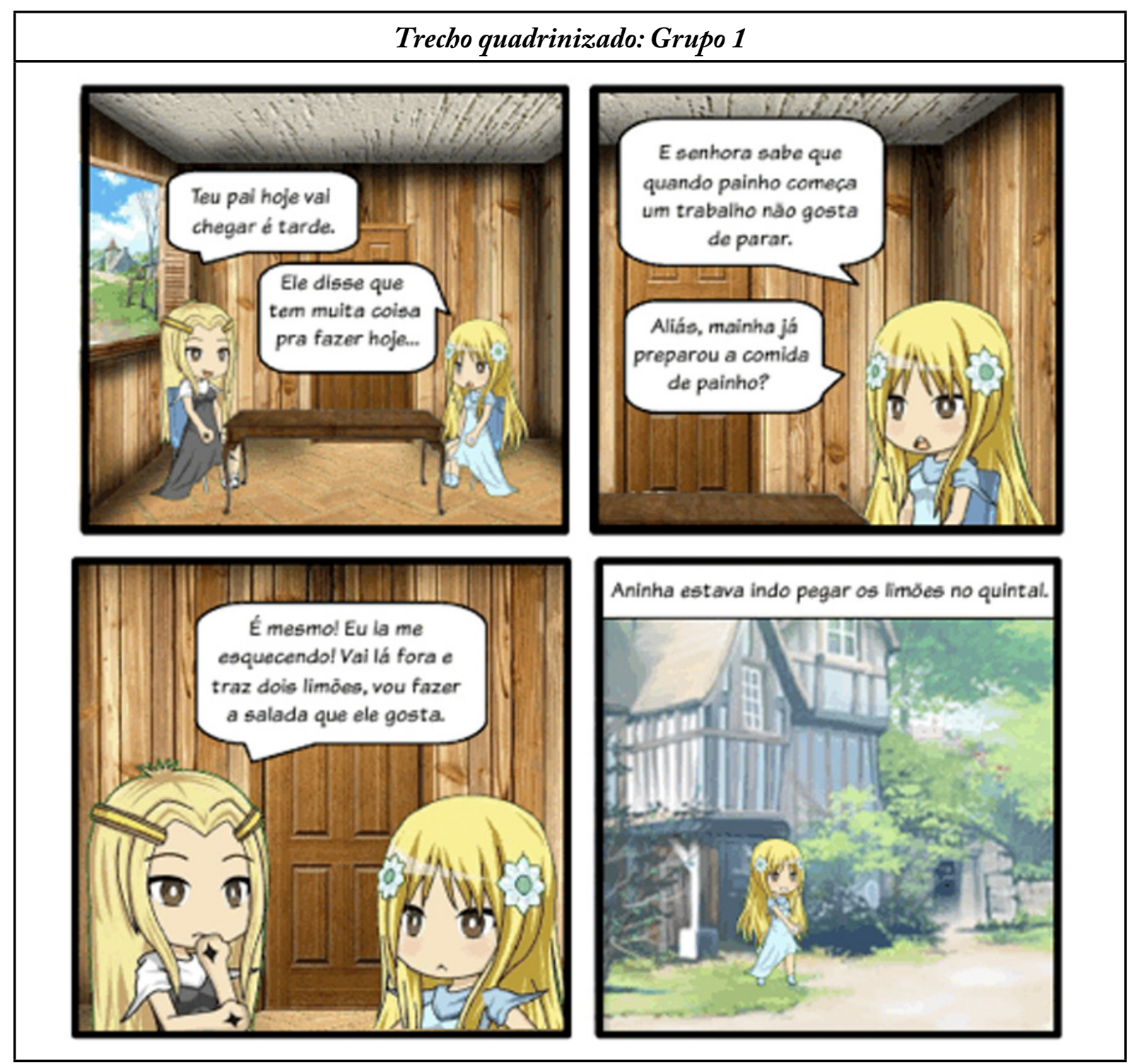

Quadro 1: Comparação do trecho inicial da peça $O$ juiz de paz da roça e sua quadrinização (GRUPO 1).

No trabalho do Grupo 2, as cenas IX e X na peça, foram retextualizadas para a cena IV no quadrinho. Nesse sentido, observamos que esse grupo realizou diversas eliminações. No trecho transcrito abaixo, a estratégia de eliminação aplicou-se a quase toda a fala do juiz na cena. Os trechos abaixo indicados em negrito foram os utilizados no quadrinho. Destacamos, aqui, o emprego da estratégia de substituição

LEITÃO, A. A. P. Do teatro aos quadrinhos: uma experiência de leitura literária e escrita multimodal Todo conteúdo da Linha D'Água está sob Licença Creative Commons Attribution-NonCommercial 4.0 International License 
Linha D'Água (Online), São Paulo, v. 33, n. 2, p. 69-90, maio-ago. 2020

com vistas à simplificação da história, já que no quadrinho temos paráfrases dos trechos destacados a fim de adequar o registro linguístico para a época atual.

Cremos ser relevante destacar que a descrição da cena na peça foi substituída por uma sala luxuosa, mesmo sendo na roça. Isso nos permite inferir que, para os estudantes, a representação do cargo de juiz, independentemente de onde ele atue, se campo ou cidade, deve ser feita a partir da indicação da riqueza e do luxo. Nossa inferência apoia-se também no fato de que os estudantes não perceberam que o juiz na roça, naquele contexto de época e na sua representação na peça, não tinha um gabinete para despachar os requerimentos. Isso era feito em sua própria casa, o que implica falta de estrutura governamental para dissociar a ação profissional do espaço pessoal.

Ainda em relação à descrição do juiz, cabe observar que mesmo a peça trazendo a descrição de sua roupa, a representação dele na imagem do personagem quadrinizado é diferente. Acreditamos que para o objetivo da criação do personagem para o quadrinho esse dado seja irrelevante, todavia, para analisarmos o nível de leitura realizado pelos estudantes, tal mudança na roupa seja um dado significativo. Isso porque a ampliação do repertório literário, uma das características promotoras do letramento literário proposta por Cosson (online) e discutida acima, deve envolver, também, a ampliação do repertório linguístico. Essa ampliação necessariamente passa pelo reconhecimento de que modificar um vocábulo ou uma sequência descritiva, como é o caso na peça, implica mudança de significado. A caracterização do juiz "vestido de calça branca, rodaque de riscado, chinelas verdes e sem gravata” (PENA, online) está em consonância com o cenário que é composto por uma "[m]esa no meio com papéis; cadeiras" (PENA, online). Essa mudança reforça nossa inferência acerca da construção social que os estudantes têm da imagem de um juiz ao mesmo tempo que aponta para falta de compreensão do contexto social da época apresentado pela peça.

Houve, também, o emprego da estratégia de inserção de modos muito distintos. Em primeiro lugar, os estudantes criaram um narrador, representado pelos quadros narrativos no quadrinho. Em seguida, ao final da fala do juiz, momento em que ele escuta bateram à porta, houve a criação de uma onomatopeia, algo que na peça é indicado como uma ação a ser realizada pelo ator. Esse trecho é

LEITÃO, A. A. P. Do teatro aos quadrinhos: uma experiência de leitura literária e escrita multimodal Todo conteúdo da Linha D'Água está sob Licença Creative Commons Attribution-NonCommercial 4.0 International License 
Linha D’Água (Online), São Paulo, v. 33, n. 2, p. 69-90, maio-ago. 2020

particularmente problemático nesse sentido porque, por um lado, a inserção da onomatopeia foi adequadamente empregada, mas por outro há uma quebra na lógica da narrativa. Observamos que no segundo quadrinho há a presença do narrador afirmando que é o escrivão que bate e mesmo assim o juiz faz a pergunta "Quem é?" e a resposta é dada, no terceiro quadrinho, pelo escrivão. Assim, o par informacional dado-novo é disjunto pois ele, na construção dessa cena, organizase como dado-dado. Não houve informação nova e a incongruência da pergunta do juiz no segundo quadrinho reforça isso.

Esse grupo utilizou, além do software LibreOffice Draw, para montagem das cenas, o site sp-studio.de para a criação dos personagens. No entanto, mesmo com os módulos, observamos que diversos problemas foram identificados na produção final, ainda que a história quadrinhos tenha sido produzida adequadamente.

No trecho indicado no Quadro 2, destacamos que o tamanho e o tipo das fontes utilizadas tornaram o texto ilegível (quadrinho 1) e sem uniformidade (quadrinho 1 em relação aos demais), que as expressões faciais dos personagens, em especial o olhar e a movimentação da boca, permanecem iguais nos quadrinhos 1 , 2 e 3 e que não houve uniformidade no tamanho dos quadros e sua distribuição na página, como se pode observar nas miniaturas (Quadro 3) de onde os quadrinhos analisados foram retirados, em comparação com outro trecho quadrinizado. Também em relação ao olhar, no último quadro do trecho selecionado podemos notar que o juiz muda o olhar e a movimentação da boca, no entanto, o escrivão mantém o olhar para o leitor e tem expressão facial idêntica à do juiz.

Diante disso, consideramos que mesmo havendo uma prática situada e uma instrução aberta, para esse grupo, a compreensão dos significados visual, espacial e de modelos multimodais possibilitou apenas parcialmente o desenvolvimento dos multiletramentos a partir da pedagogia proposta.

LEITÃO, A. A. P. Do teatro aos quadrinhos: uma experiência de leitura literária e escrita multimodal 
Linha D’Água (Online), São Paulo, v. 33, n. 2, p. 69-90, maio-ago. 2020

Trecho original: $O$ juiz de paz da roça

CENA IX

Sala em casa do Juiz de Paz. Mesa no meio com papéis; cadeiras. Entra o Juiz de Paz vestido de calça branca, rodaque de riscado, chinelas verdes e sem gravata.

JUIZ - Vamo-nos preparando para dar audiência. (Arranja os papéis.) O escrivão já tarda; sem dúvida está na venda do Manuel do Coqueiro... O último recruta que se fez já vai-me fazendo peso. Nada, não gosto de presos em casa. Podem fugir, e depois dizem que o juiz recebeu algum presente. (Batem à porta.) Quem é? Pode entrar. (Entra um preto com um cacho de bananas e uma carta, que entrega ao Juiz. Juiz, lendo a carta:) "Ilmo. Sr. - Muito me alegro de dizer a V. Sa. que a minha ao fazer desta é boa, e que a mesma desejo para V. Sa. pelos circunlóquios com que lhe venero." (Deixando de ler:) Circunlóquios....... Que nome em breve! O que quererá ele dizer? Continuemos.

(Lendo:) Tomo a liberdade de mandar a V. Sa. um cacho de bananas-maçãs para V. Sa. comer com a sua boca e dar também a comer à Sra. Juíza e aos Srs. Juizinhos. V. Sa. há de reparar na insignificância do presente; porém, Ilmo. Sr., as reformas da Constituição permitem a cada um fazer o que quiser, e mesmo fazer presentes; ora, mandando assim as ditas reformas, $\mathrm{V}$. Sa. fará o favor de aceitar as ditas bananas, que diz minha Teresa Ova serem muito boas. No mais, receba as ordens de quem é seu venerador e tem a honra de ser - Manuel André de Sapiruruca." Bom, tenho bananas para a sobremesa. Ó pai, leva estas bananas para dentro e entrega à senhora. Toma lá um vintém para teu tabaco. (Sai o negro.) O certo é que é bem bom ser Juiz de Paz cá pela roça. De vez em quando temos nossos presentes de galinhas, bananas, ovos, etc., etc. (Batem à porta.) Quem é?

ESCRIVÃO, dentro - Sou eu.

JUIZ - Ah, é o escrivão. Pode entrar.

\section{CENA X}

ESCRIVÃO - Já intimei Manuel João para levar o preso à cidade.

JUIZ - Bom. Agora vamos nós preparar a audiência. (Assentam-se ambos à mesa e o Juiz toca a campainha.) Os senhores que estão lá fora no terreiro podem entrar.(Entram todos os lavradores vestidos como roceiros; uns de jaqueta de chita, chapéu de palha, calças brancas de ganga, de tamancos, descalços; outros calçam os sapatos e meias quando entram, etc. Tomás traz um leitão debaixo do braço.) Está aberta a audiência. Os seus requerimentos?

[continua]

LEITÃO, A. A. P. Do teatro aos quadrinhos: uma experiência de leitura literária e escrita multimodal 
Linha D'Água (Online), São Paulo, v. 33, n. 2, p. 69-90, maio-ago. 2020

[continuação]

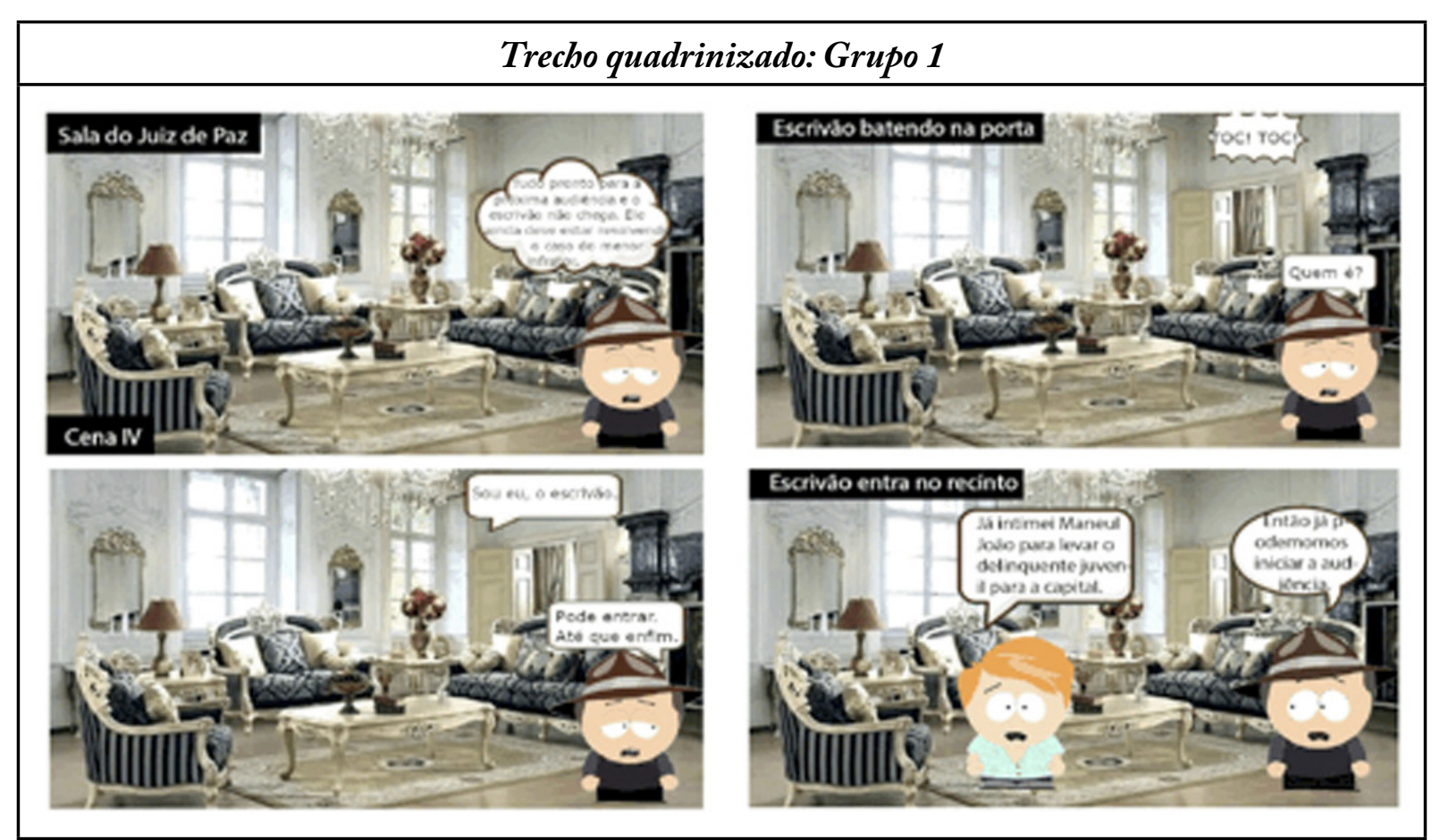

Quadro 2: Comparação do trecho inicial da peça $\mathrm{O}$ juiz de paz da roça e sua quadrinização (GRUPO 2).

LEITÃO, A. A. P. Do teatro aos quadrinhos: uma experiência de leitura literária e escrita multimodal 
Linha D'Água (Online), São Paulo, v. 33, n. 2, p. 69-90, maio-ago. 2020

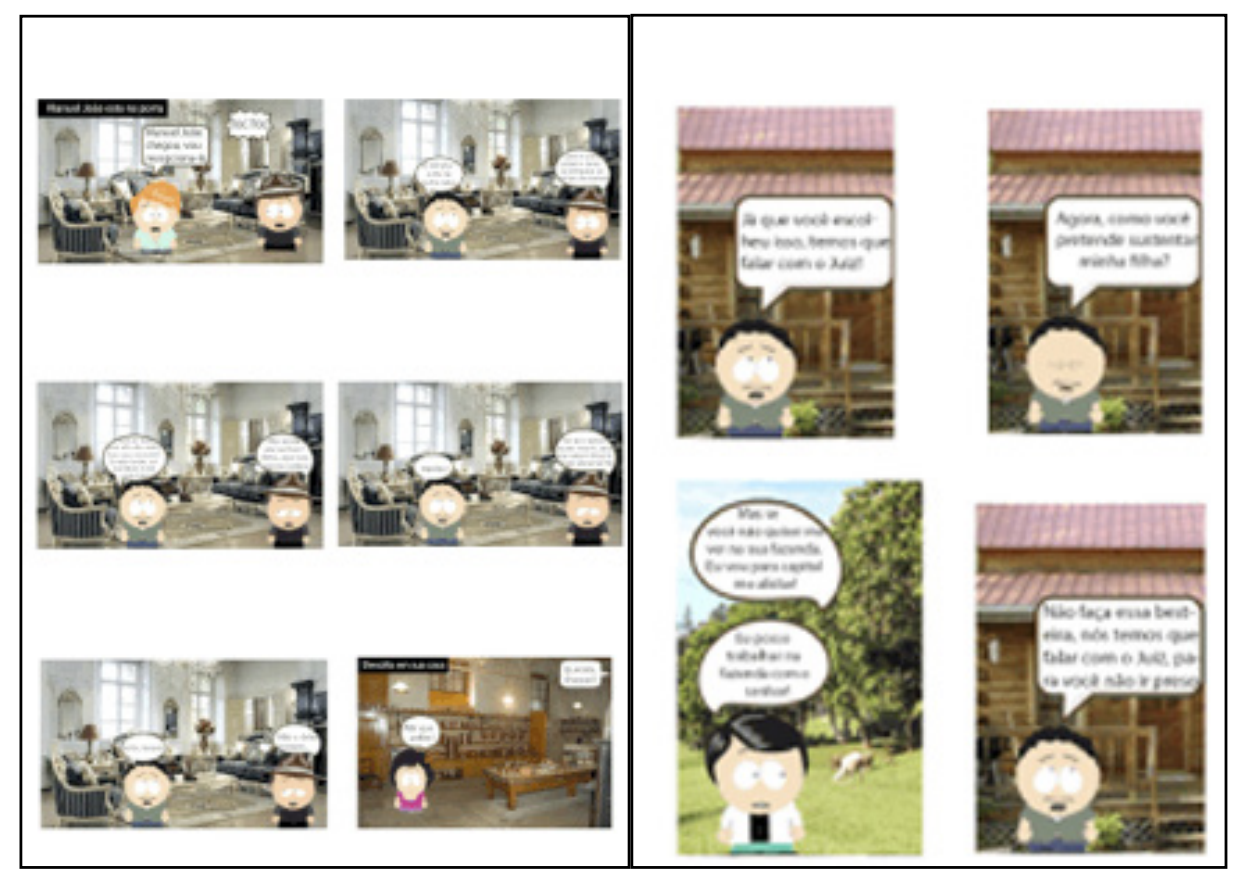

Quadro 3: Miniatura da página quadrinizada das cenas IX e X da peça.

\section{Considerações finais}

Diante do exposto, parece-nos sensato considerar que a pedagogia dos multiletramentos quando articulada adequadamente com outras propostas teóricas para o ensino da leitura e escrita de gêneros textuais e do letramento literário pode contribuir para uma prática transformada, que permite aos alunos, como produtores de significado, tornarem-se designers do futuro social (GRUPO DE NOVA LONDRES, 1996, online).

No entanto, para que a articulação entre as diferentes propostas teóricas discutidas aqui possa ser efetiva em sala de aula, de modo a possibilitar que os estudantes se tornem designers de um futuro social, torna-se imprescindível considerar alguns aspectos. Em primeiro lugar, apontamos que a criação e consolidação de uma comunidade de leitores literários no espaço da escola só é possível se os docentes perceberem a relevância de incluir, novamente, a literatura nas aulas de língua portuguesa. Obviamente, não nos referimos à literatura enquanto historiografia literária, mas a leitura frequente e a análise das particularidades de cada texto literário.

LEITÃO, A. A. P. Do teatro aos quadrinhos: uma experiência de leitura literária e escrita multimodal Todo conteúdo da Linha D'Água está sob Licença Creative Commons Attribution-NonCommercial 4.0 International License 
Linha D'Água (Online), São Paulo, v. 33, n. 2, p. 69-90, maio-ago. 2020

Em segundo lugar, o processo de retextualização, qualquer um dos 4 tipos propostos por Marcuschi (2004), só se proporciona uma melhoria da escrita havendo espaço no planejamento docente para diversas reescritas e correções. Esta última alerta os estudantes acerca do que precisa ser melhorado e a primeira permite que os estudantes percebam a importância da escrita enquanto forma de expressão que necessita de prática. Ou seja: reescrever um texto, de qualquer gênero, apenas uma vez em sala de aula, não garantirá a melhoria da escrita discente.

Por fim, consideramos que as tecnologias digitais não podem mais ser consideradas como um diferencial, como uma ferramenta exótica da qual se valem os docentes para ministrar uma aula melhor, diferenciada. As tecnologias digitais, atualmente, ocupam lugar de destaque nas vidas de professores e alunos e tal lugar precisa ser inserido como conteúdo programático dos componentes curriculares, não apenas para o ensino de línguas. $\mathrm{O}$ uso de ferramentas tecnológicas para criação de quadrinhos, edição de áudio e vídeo, elaboração de pôsteres acadêmicos, software de legendagem de vídeos, entre tantas outras permitem uma melhor compreensão das ações de linguagem (BRONCKART, 2003) que fazem parte do nosso cotidiano.

\section{Referências}

BAKHTIN, M. Estética da criação verbal. São Paulo: Martins Fontes, 2003.

BRASIL. MEC. Secretaria de Educação Básica. Ministério da Educação. Orientaçôes Curriculares para o Ensino Médio - Linguagens, códigos e suas tecnologias. Brasília: Ministério da Educação, Secretaria de Educação Básica, 2006.

BRASIL. MEC. Secretaria de Educação Média e Tecnológica. Parâmetros curriculares nacionais: ensino médio. Brasília, 1999.394p.

BRASIL. MEC. Secretaria de Educação Média e Tecnológica. PCNs+ Ensino Médio:orientações educacionais complementares aos Parâmetros Curriculares Nacionais. Brasília, 2002.144 p

BRONCKART, Jean-Paul. Atividade de linguagem, textos e discursos: por um interacionismo sóciodiscursivo. São Paulo: Educ, 2003. 353 p. Trad. Anna Rachel Machado, Péricles Cunha.

LEITÃO, A. A. P. Do teatro aos quadrinhos: uma experiência de leitura literária e escrita multimodal Todo conteúdo da Linha D’Água está sob Licença Creative Commons Attribution-NonCommercial 4.0 International License 
Linha D'Água (Online), São Paulo, v. 33, n. 2, p. 69-90, maio-ago. 2020

COSSON, R. Letramento literário. In: FRADE, I. C. A. S; VAL, M. da G. C. G; BREGUNCI, M. das G. C. Glossário Ceale de termos de Alfabetização, leitura e escrita para educadores. Belo Horizonte, CEALE/Faculdade de Educação da UFMG. 2014. Disponível em: <http://ceale. fae.ufmg.br/app/webroot/glossarioceale/verbetes/letramento-literario >. Acesso em: Acesso em: 01 fev. 2019.

DOLZ, J., NOVERRAZ, M. e SCHNEUWLY, B. Sequências didáticas para o oral e a escrita: apresentação de um procedimento. In: DOLZ, J. e SCHNEUWLY, B. Gêneros orais e escritos na escola. Campinas, SP: Mercado de Letras, 2004.

FIORIN, J. L. Introdução ao pensamento de Bakbtin. São Paulo: Contexto, 2018.

GRUPO DE NOVA LONDRES. A Pedagogy of Multiliteracies: Designing Social Futures. 1996. Disponível em:<http://wwwstatic.kern.org/filer/blogWrite44ManilaWebsite/paul/articles/A_ Pedagogy_of_Multiliteracies_Designing_Social_Futures.htm\#11> Acesso em: 02 jun. 2009.

MARCUSCHI, L. A. Da fala para escrita: atividades de retextualização. São Paulo: Cortez, 2004.

MARTINS PENA, L. C. O Juiz de paz da roça. Ministério da Cultura. Fundação Biblioteca Nacional. Departamento Nacional do Livro. Disponível em: <http://www.dominiopublico.gov. br/download/texto/bn000103.pdf>. Acesso em: 10 mar. 2019.

MARTINS PENA, L. C. Os dous ou o inglês maquinista. Ministério da Cultura. Fundação Biblioteca Nacional. Departamento Nacional do Livro. Disponível em: <http://www.dominiopublico.gov.br/download/texto/bn000154.pdf>. Acesso em: 10 mar. 2019.

PINTO, M. Alguns descompassos no ensino de literatura: documentos e práticas oficiais. In: Remate de Males. Campinas-SP, (34.2): p. 459-476, Jul./Dez. 2014

TRAVAGLIA, N. G. A tradução numa perspectiva textual. Tese de doutorado. USP: São Paulo, 1993.

Recebido: 29/11/2019

Aprovado: 08/03/2020

LEITÃO, A. A. P. Do teatro aos quadrinhos: uma experiência de leitura literária e escrita multimodal Todo conteúdo da Linha D’Água está sob Licença Creative Commons Attribution-NonCommercial 4.0 International License 